\title{
Public and farmer perceptions of dairy cattle welfare in the United States
}

\author{
C. A. Wolf, ${ }^{* 1}$ G. T. Tonsor, † M. G. S. McKendree, † D. U. Thomson, $\ddagger$ and J. C. Swanson§ \\ *Department of Agricultural, Food, and Resource Economics, Michigan State University, East Lansing 48824 \\ †Department of Agricultural Economics, and \\ ‡Department of Diagnostic Medicine and Pathobiology, Kansas State University, Manhattan 66506 \\ §Department of Animal Science, Michigan State University, East Lansing 48824
}

\section{ABSTRACT}

This research used surveys of the public and dairy farmers in the United States to assess perceptions and attitudes related to dairy cattle welfare. Sixty-three percent of public respondents indicated that they were concerned about dairy cattle welfare. Most public respondents agreed that animal welfare was more important than low milk prices but that the average American did not necessarily agree. Most public respondents had not viewed media stories related to dairy cattle welfare. Respondents who had viewed these stories did so on television or Internet. The United States Department of Agriculture (USDA) was viewed as the most accurate source of information related to dairy cattle welfare, followed by the Humane Society of the United States (HSUS) and the American Veterinary Medicine Association (AVMA). Both public and dairy farmer respondents viewed farmers as having the most influence on dairy cattle welfare. However, there was a general pattern of public respondents indicating that groups including USDA, HSUS, and AVMA had a relatively larger influence on dairy cattle welfare than did farmer respondents. In contrast, dairy farmers indicated that individual actors-farmers, veterinarians, consumers-had more influence than the public indicated. When asked about production practices, most public respondents indicated that they would vote for a ban on antibiotic use outside of disease treatment or for the mandated use of pain control in castration. However, a minority indicated they would vote to ban the use of recombinant bovine somatotropin (rbST) or to pay a premium for milk produced without rbST. With respect to explaining public support for the production practice bans and limits, respondents were more likely to vote for the restrictions if they were older, female, had higher income, or had viewed animal welfare stories in the media.

Received November 10, 2015.

Accepted March 8, 2016.

${ }^{1}$ Corresponding author: wolfch@msu.edu
Key words: animal welfare, information sources, public perceptions, multinomial logit

\section{INTRODUCTION}

In recent years, public scrutiny of production practices in livestock agriculture has increased. Curtis (1987) noted that production practices must have scientific evidence behind them to justify their existence. However, Curtis (1987) asserted that the public was ignorant of production practices and would often find even scientifically defensible practices objectionable. The logical solution then might be education to set context for understanding production practices on modern operations. Fraser et al. (1997) defined animal welfare as having 3 dimensions: animal functioning, animal feeling, and animal ability to live a reasonably natural life. The best animal welfare-related policies for the dairy industry will address all 3 dimensions. The ultimate goal for the industry and researchers is to improve the lives of cattle and farmers (von Keyserlingk et al., 2009).

Ellis et al. (2009) noted that animal welfare concerns are likely to become more important in the future and that consumers are removed from food production and therefore do not have accurate knowledge of the food chain. Ellis et al. (2009) found that most respondents in the UK would pay more for "good" dairy welfare and suggested improved consumer education and clear labeling to improve market signals for dairy cattle welfare. Boogaard et al. (2011) described the complicated relationship that society has with modern production animal agriculture. Although the public appreciates the supply of relatively cheap and very safe food, they have concerns about the size and scale (and production practices that accompany these technology sets) of modern operations that relate to impacts on the environment and animal welfare. Boogaard et al. (2011) studied Dutch citizens and found that those with experience and knowledge of farming were the most content with contemporary dairy farming. Similarly, other studies have found discrepancies in animal welfare assessment 
between farmers and the public (Te Velde et al., 2002; Vanhonacker et al., 2008; Miele et al., 2011).

In recent years in the United States, undercover videos have periodically been released of poor cattle conditions and abuse on dairy farms, which focuses public attention on dairy cattle welfare issues (e.g., Webb, 2010; Barrett and Bergquist, 2013; Miller, 2014). Regardless of how prevalent these poor conditions are in the industry, these videos have spurred a host of changes within the industry. In the United States, industry-wide changes in livestock, poultry, and dairy production practices have generally occurred through 2 methods: (1) legislative or ballot initiatives, and (2) retailers requiring suppliers to adopt standards or practices (Mench, 2003). For example, residents in many states have determined, through ballot initiatives or legislation, that particular livestock production practices will be phased out or banned due to associated undesirable animal welfare impacts. Specific to the dairy industry, tail docking was banned in California - the largest milk-producing state - as of January 1, 2010. Alternatively, many food service establishments, from grocers to restaurants, are increasingly purchasing their food from "humanely raised" sources or phasing out specific practices related to animal confinement. Although most attention and legal changes to date have focused on other livestock sectors, the US dairy industry is increasingly aware that these pressures affect them as well. Recognizing these methods of change makes it clear that the perceptions and opinions of the public in their role as both consumers and voters are of critical importance.

In response to the increased scrutiny of dairy farm management practices related to cow welfare, US dairy farm organizations created a voluntary program, Farmers Assuring Responsible Management (FARM), to establish and verify farm practices and to provide assurance to the public at large (NMPF, 2014). This program is intended to lead on dairy cattle welfare issues. For example, the National Milk Producers Federation announced in 2015 that tail docking among their member-farms would end nationwide on December 31, 2016 (Sjostrom, 2015). In addition to this producer program, various animal welfare-related groups have created their own programs that have certification and labeling for marketing purposes (e.g., Humane Farm Animal Care, 2014).

Because of increased scrutiny of production practices, it is critical that US dairy farmers be aware of public perceptions. With knowledge of these perceptions and attitudes, dairy farmers can make informed decisions about production practices used on their farms while enhancing public trust and maintaining their social license. This research aims to assess US public and dairy farmer attitudes and perceptions about dairy cattle welfare to compare the groups as well as to provide a benchmark for discussion and monitoring.

\section{MATERIALS AND METHODS}

The public and dairy farmer surveys were written by a team of Michigan State University (East Lansing) and Kansas State University (Manhattan) researchers in fall 2013 and spring 2014. The surveys were scrutinized by industry and academic experts. Both surveys were anonymous and approved by Michigan State University's Human Research Protection Program. Each of the surveys and samples are described in this section followed by the statistical and regression analysis used to examine results.

\section{Public Survey}

A national online survey was administered in April 2014 to collect information about US public milk-purchasing habits, perceptions of dairy cow welfare, and demographic characteristics, including age, education, sex, household size, and income (Wolf et al., 2015b). The public survey was administered to US households online, with participants being recruited from a large opt-in panel that has been used effectively in other research (e.g., Louviere et al., 2008; Tonsor, 2011). Participants were recruited from a panel maintained by Survey Sampling International (SSI, Shelton, CT) to be a sample representative of primary US household shoppers based on age, income, and state of residence. We focused on respondents who were the primary household food shopper, as we were interested in their purchasing and consumption preferences.

In total, 2,001 completed surveys were collected. The public survey asked questions about the respondent's concern about dairy cattle welfare, agreement with statements regarding guiding dairy industry principles, the accuracy of dairy cattle welfare media sources, the ability of groups to influence dairy cattle welfare, and whether he or she would vote or pay for specific production practices.

\section{Dairy Farmer Survey}

The dairy farmer survey was administered by mail in March and April 2014 (Wolf et al., 2015a). Dairy farmers were randomly drawn from lists of production operations licensed to ship milk acquired from Departments of Agriculture in 7 states, including California, Florida, Indiana, Michigan, New Mexico, Vermont, and Wisconsin. Together, these states accounted for $47 \%$ of US milk production in 2014 (96.9 billion of 206 billion 
pounds total; USDA-NASS, 2015). These states are also from major milk-producing regions across the country, including the Upper Midwest (WI, MI, IN), the northeast (VT), southeast (FL), southwest (NM), and Pacific $(\mathrm{CA})$. Following the tailored design method, the initial survey was sent, followed by a reminder card 3 wk later and a second survey $3 \mathrm{wk}$ after the reminder (Dillman et al., 2009). After deleting sheep, goat, and institutional producers such as university herds, 2,500 names and addresses were randomly drawn. After accounting for 86 invalid or outdated addresses, 2,414 surveys were sent out, resulting in 692 usable responses for a $28.7 \%$ response rate. The producer survey collected information on the operation and operator, including herd size, acres operated, milk production per cow, operator age, operator education, and farm income. As in the public survey, farmers were asked about the ability of various groups and individuals to influence dairy cattle welfare and what they thought the public would vote or pay for in specific production practices.

\section{Statistical Analysis}

Many of the questions were asked with a Likert scale response such as $1=$ least effective/desirable to $5=$ most effective/desirable, $6=$ don't know (or strongly agree to strongly disagree; or most accurate to least accurate depending on the issue under consideration). For the Likert questions, we used means to summarize responses. The conditional means are the average of those who did not answer "don't know," although we also considered how many respondents selected "don't know."

To compare across the public and dairy farmer surveys, we used Welch's $t$-tests assuming unequal variances calculated using Excel (Microsoft Corp., Redmond, WA). This test was used because the samples had unequal sizes (2,001 public versus 656 producer respondents) and unequal variance.

\section{Multinomial Logit Estimation}

The empirical estimation used to explain voting and premium intentions was a multinomial logit. With respect to voting or premium intentions for the production practices in question, there were 3 possible outcomes: $j$ $=1$ when the answer was "yes," $j=2$ when "no," $j=$ 3 when the respondent answered "don't know." Define

$$
\begin{gathered}
D_{i j}=1 \text { if } \pi_{i j}=\max \left(\pi_{i 1}, \pi_{i 2}, \pi_{i 3}\right) \\
0 \text { otherwise, }
\end{gathered}
$$

where $i=1, \ldots, n$ to index individual; and $j=1,2,3$ to index outcome. Thus, for example, $D_{i 2}$ is a binary variable taking a value of 1 when voting "no" results in the largest expected utility $(\pi)$. The discrete decision of how to vote can be estimated using many different functional forms depending on the density function of the error term. For example, a logit model results when the distribution is assumed logistic (Apslund et al., 1989). When the random disturbance $e_{i j}$ has the density function $f(u)=e^{\left(-u_{j}-e^{u_{j}}\right)}$ and distribution function $\mathrm{F}\left(u_{j}<u\right)=e^{e^{-u}}$, where $\mathrm{u}$ is part of the standard Gumbel distribution underlying traditional multinomial analyses, the probability that the $i$ th respondent makes the $j$ th choice can be written as a multinomial logit function (Maddala, 1983):

$$
\operatorname{Prob}\left(D_{i j} 1 \mid \mathbf{Z}\right)=\frac{e^{Z_{i} B_{j}}}{\sum_{j=1}^{J} e^{Z_{i} B_{j}}},
$$

where $\mathbf{Z}$ is a vector of respondent characteristics; $i=$ $1, \ldots, n ; j=1,2,3$; and $\beta$ is a vector of coefficients to be estimated. Respondent characteristics include age, education, income, sex, milk consumption, household size, region, indication of animal welfare concern, and viewing of animal welfare media. All estimations were performed in Stata (version 12; Stata, College Station, TX). Coefficients from multinomial logit estimation can be difficult to interpret because they are relative to the base outcome. Therefore, we report the marginal effect of changing the explanatory variables on the probability of observing the outcome and provide the coefficient estimates in the Appendix Table A1.

\section{RESULTS AND DISCUSSION}

\section{Public Survey Summary Statistics}

Summary statistics of respondent demographics are provided in Table 1. As the survey was aimed at the primary shopper, respondents were $70 \%$ female compared with the actual $51 \%$ of Americans that are female (US Census Bureau, 2015). Average household size was about 2.4, slightly smaller than the US Census reported for the general population (2.7 people). The average age of respondents was $51.3 \mathrm{yr}$, with more than half of respondents being $55 \mathrm{yr}$ or older. The median age of public survey respondents was 52 compared with a US median age of 37 yr (US Census Bureau, 2015). Respondent educational level was higher than the US average. In our sample, $97 \%$ graduated high school compared with $86 \%$ of the US population, and 
Table 1. United States public survey summary statistics

\begin{tabular}{|c|c|}
\hline Variable & Value \\
\hline \multicolumn{2}{|l|}{ Sex (\% of respondents) } \\
\hline Male & 30 \\
\hline Female & 70 \\
\hline \multicolumn{2}{|l|}{ Household size (no.) } \\
\hline Average household size & 2.4 \\
\hline Average number of adults & 1.9 \\
\hline Average number of children & 0.5 \\
\hline Average age $(\mathrm{yr})$ & 51.3 \\
\hline \multicolumn{2}{|l|}{ Education level ( $\%$ of respondents) } \\
\hline$<$ High school & 2.4 \\
\hline High school & 37.6 \\
\hline Associate's or trade degree & 26.3 \\
\hline Bachelor's degree & 23.8 \\
\hline Graduate or advanced degree & 9.9 \\
\hline \multicolumn{2}{|l|}{ Household milk consumption (\% of respondents) } \\
\hline$\geq 7$ times/wk & 41.8 \\
\hline$\overline{4}-6$ times/wk & 19.1 \\
\hline $2-3$ times/wk & 15.1 \\
\hline$\leq 1 /$ wk & 14.1 \\
\hline $\bar{N}$ ever & 5.2 \\
\hline Average household food expenditure $(\$ /$ wk $)$ & 114.83 \\
\hline
\end{tabular}

about $34 \%$ held a bachelor's or higher college degree, compared with $28 \%$ of the US population (US Census Bureau, 2015). Thus, the public sample was on average older, more educated, and more female than the US population in general but spanned a broad range of all those demographics.

Over $80 \%$ of respondent households had annual incomes of less than $\$ 75,000$, with almost one-third of respondents coming from households with annual incomes between $\$ 25,000$ and $\$ 50,000$. For comparison, the median US household income was $\$ 53,046$ (US Census Bureau, 2015). Average weekly food expenditure was approximately $\$ 115 /$ week. Survey respondent frequency of milk consumption is also summarized in Table 1. Overall, about two-thirds of respondents reported consuming milk 4 or more times per week. About $14 \%$ reported consuming milk less than once per week, and about $5 \%$ of respondents indicated they never drank milk. For this reason, we refer to these respondents as the "public" rather than "consumers." For purposes of examining public perceptions, especially with respect to potential legal or regulatory issues related to dairy cattle welfare, the public is most relevant, rather than strictly dairy consumers.

\section{Farmer Survey and Summary Statistics}

Table 2 displays summary statistics of dairy farmer respondents. On average, the herds had 346 milk cows, which is larger than the average US operation with milk cows, according to the USDA, but is in line with typical commercial dairy farm operations (USDA-NASS, 2015). Annual milk production per cow was 24,478 lb., higher than the average US milk cow, which produced 22,258 lb. in 2014 (USDA-NASS, 2015). Average primary dairy farm operator age was $51.9 \mathrm{yr}$, identical to the average primary dairy farm operator age from the most recent agricultural census (USDA-NASS, 2012). About $40 \%$ of operators had at least some college education, and most operations derived at least $75 \%$ of the farm revenue from the dairy enterprise.

\section{Public Views of Dairy Cattle Welfare}

When asked whether they were concerned with dairy cattle welfare in the United States, $63.4 \%$ of public respondents answered yes, $20.5 \%$ answered no, and the remaining $16.1 \%$ indicated that they did not know. Other recent research found that most Americans are concerned with the welfare of cows on dairy farms (Cardoso et al., 2016). To examine the potential trade-offs, respondents were asked about their level of agreement with statements about cattle welfare or well-being versus milk price and cattle welfare, or well-being versus farm profitability. Past research has shown that respondents

Table 2. United States dairy farmer survey summary statistics

\begin{tabular}{lcc}
\hline Variable & Mean & SD \\
\hline Milk cows (no.) & 346 & 946 \\
Milk/cow (lb.) & 24,478 & 8,489 \\
Operator age (yr) & 51.9 & 12.8 \\
Operator experience (yr) & 31.4 & 15.3 \\
Operator education (\% of respondents) & 17.8 \\
<High school & 41.3 \\
High school & 20.3 & \\
Technical school & 16.7 & \\
Bachelor's degree & 3.8 & \\
Graduate or advanced degree & & \\
Income from dairy enterprise (\% of respondents) & 7.7 & \\
$<25 \%$ & 13.3 & \\
$26-50 \%$ & 17.7 & \\
$51-75 \%$ & 61.3 & \\
$>75 \%$ & & \\
\hline
\end{tabular}


Table 3. United States public agreement with statements regarding dairy cattle

\begin{tabular}{|c|c|c|}
\hline Statement & $\begin{array}{l}\text { Average } \\
\text { score }^{1}\end{array}$ & $\begin{array}{c}\text { Don't } \\
\text { know }(\%)\end{array}$ \\
\hline Low milk prices are more important than the well-being of cattle & 3.48 & 7.2 \\
\hline The average American thinks low milk prices are more important than the well-being of cattle & 2.34 & 11.0 \\
\hline The average American believes that dairy farmers face a trade-off between profitability and animal welfare & 2.21 & 16.3 \\
\hline
\end{tabular}

${ }^{1}$ Average across respondents that did not answer "don't know" based on the Likert scale: $1=$ strongly agree to $5=$ strongly disagree.

often view the perceived responses of typical or average citizens as differing from their own (Olynk et al., 2010). Inquiring about what the average person thinks - referred to as indirect questioning - has been shown to alleviate social desirability bias (Fisher, 1993; Lusk and Norwood, 2009). In this case, social desirability bias would be answering in a way that makes one appear more sensitive to the issue in question than they truly are. With this in mind, it is informative to consider the responses to the statements in Table 3. Although 57\% of respondents disagreed or strongly disagreed with the statement "low milk prices are more important than the well-being of cattle," resulting in an average score of 3.48 , these respondents thought the average American would disagree or strongly disagree only $23 \%$ of the time, for an average score of 2.34. The presence of social desirability bias would suggest that the answers related to the "average American" are likely closer to actual sentiment and respondents were more concerned about low milk prices than the first question would indicate. In contrast, respondents thought that they and the average American had about the same level of agreement, 2.2 to 2.3 , with the statement that "dairy farmers face a trade-off between profitability and animal welfare." In the case of the latter statement, the general opinion leaned toward agreement that dairy farmers faced a trade-off between profitability and animal welfare.

\section{Information Sources and Accuracy of Dairy Cattle Welfare}

There have been several instances of undercover videos and related print, Internet, and television reports related to alleged abuse of dairy cattle in recent years (e.g., Miller, 2014; Paul, 2015). Respondents were asked whether they had noticed any of these reports and, if so, on which media type. A large majority of respondents, $70 \%$, reported they had not seen any media stories regarding dairy cattle welfare, so $30 \%$ of respondents had noticed stories or reports on this subject (Table 4). Respondents who had noticed media stories on dairy cattle welfare could have done so on multiple media types (more than one answer was possible, so the percentages add to more than 100\%). The most common was television followed by Internet. Combined, these sources accounted for about two-thirds of media views. Both television and Internet lend themselves to the undercover videos, which have been a common mode of stories related to dairy cattle welfare. Less common were printed newspapers and magazines.

Many sources might supply information regarding cattle welfare from producers to processors to grocers and restaurants. Table 5 summarizes US public respondent views about the accuracy of many parties involved with the US dairy industry. Respondents gave the USDA the highest mean score. The Humane Society of the United States (HSUS) was viewed as the second most accurate, essentially tied with the American Veterinary Medical Association (AVMA). The third tier of accuracy included university scientists, American Farm Bureau (AFB), National Milk Producers Federation (NMPF), local veterinarians, International Dairy Foods Association (IDFA), and People for the Ethical Treatment of Animals (PETA). Dairy cattle welfare information from grocers and restaurants was viewed as relatively less accurate. Note, however, that approxi-

Table 4. Public recollection of media stories regarding dairy cattle welfare in the United States

\begin{tabular}{lcc}
\hline Statement & Yes $(\%)$ & No $(\%)$ \\
\hline I have not seen any media stories regarding dairy cattle welfare & 70.3 & 29.7 \\
I have seen stories regarding dairy cattle welfare on: & 18.0 & 82.0 \\
Television & 12.9 & 87.1 \\
Internet & 5.3 & 94.7 \\
Printed newspaper & 5.6 & 94.4 \\
Magazines & 2.7 & 97.3 \\
Books & 1.4 & 98.6 \\
Other media & \\
\hline
\end{tabular}


Table 5. Public views of accuracy of dairy cattle welfare information from select sources in the United States

\begin{tabular}{lcc}
\hline Source & Average score $^{1}$ & Don't know $(\%)^{\prime}$ \\
\hline National Milk Producers Federation (NMPF) & 2.33 & 36.0 \\
International Dairy Foods Association (IDFA) & 2.29 & 36.1 \\
Local veterinarian & 2.32 & 35.3 \\
American Veterinary Medical Association (AVMA) & 2.43 & 34.4 \\
American Farm Bureau (AFB) & 2.35 & 35.0 \\
United States Department of Agriculture (USDA) & 2.64 & 29.3 \\
Restaurant & 1.81 & 36.3 \\
Grocers & 1.96 & 35.2 \\
The Humane Society of the United States (HSUS) & 2.45 & 32.6 \\
People for the Ethical Treatment of Animals (PETA) & 2.29 & 32.1 \\
University scientists & 2.39 & 34.4 \\
\hline
\end{tabular}

${ }^{1}$ Average across respondents that did not answer "don't know" based on the Likert scale: 1 = very inaccurate to $5=$ very accurate.

mately one-third of respondents answered "don't know" about the accuracy of each potential source of dairy cattle welfare. This likely indicates a combination of factors, including that a large percentage of respondents indicated that they had not viewed or noticed stories on dairy cattle welfare and general unfamiliarity with agriculture and agricultural-related groups or organizations.

\section{Influences on Dairy Cattle Welfare}

Public respondents were also asked to score the ability of farmers, consumers, government, industry, and welfare-related organizations or groups to influence dairy cattle welfare. Respondents to the public survey believed the USDA and dairy farmers had the most influence over the welfare of dairy cattle (Table 6). National Milk Producers Federation - the national organization of dairy farmer cooperatives that created the FARM program to address dairy cattle welfarewas viewed as the next most influential in assuring dairy cattle welfare. The next tier of influence included American Farm Bureau (AFB), HSUS, and IDFA, which are organizations that aim to influence policy. Consumers and veterinarians were ranked in the bottom half in terms of ability to influence dairy cattle welfare of the actors examined. Respondents seemed to recognize that consumers and consumer-related groups have a role to play in assuring dairy cattle welfare but farmers - with direct daily access to cattle - have the most influence.

Dairy farmer respondents were also asked to score the ability of those same organizations or groups to influence dairy cattle welfare. Table 6 reveals that dairy producers thought that they had by far the most influence on dairy cattle welfare - and presumably the most responsibility, as well. In second place were local veterinarians, followed by dairy cooperatives, consum-

Table 6. Ability to influence dairy cattle welfare

\begin{tabular}{|c|c|c|c|c|}
\hline Group & \multicolumn{2}{|c|}{ Public respondents } & \multicolumn{2}{|c|}{ Farmer respondents } \\
\hline Dairy cooperatives & $3.60^{*}$ & 27.8 & $3.82^{*}$ & 10.2 \\
\hline National Milk Producers Federation (NMPF) & $3.99^{*}$ & 22.7 & $3.25^{*}$ & 13.6 \\
\hline International Dairy Foods Association (IDFA) & $3.85^{*}$ & 24.2 & $3.50^{*}$ & 10.7 \\
\hline American Farm Bureau (AFB) & $3.89^{*}$ & 22.6 & $3.16^{*}$ & 14.9 \\
\hline US Department of Agriculture (USDA) & $4.25^{*}$ & 15.2 & $3.56^{*}$ & 12.7 \\
\hline Consumers & $3.43^{*}$ & 17.0 & $3.57^{*}$ & 11.6 \\
\hline Restaurants & 2.93 & 20.7 & 2.86 & 12.7 \\
\hline Grocers & $3.11^{*}$ & 18.7 & $2.99^{*}$ & 12.5 \\
\hline Voters & $3.28 *$ & 19.7 & $3.13^{*}$ & 15.9 \\
\hline Humane Society of the United States (HSUS) & $3.65^{*}$ & 20.1 & $3.14^{*}$ & 13.7 \\
\hline
\end{tabular}


ers, and the USDA. Dairy producers were less likely to answer that they did not know about the influence of these groups than were the public respondents.

Comparing the relative average levels of influence between the US public and dairy farmers reveals interesting patterns. First, views were significantly different between the survey respondent groups for all influencers except restaurants and university scientists. Second, although all other actors were viewed to have different levels of influence, a clear pattern emerged. The public views were that groups exert significantly higher influence, whereas dairy farmers viewed individual actors as having more influence. The US public believed that USDA, dairy cooperatives, NMPF, IDFA, AFB, USDA, AVMA, HSUS, and PETA were significantly more influential on dairy cattle welfare than did US dairy farmers. Meanwhile, dairy farmers believed that farmers and consumers were more influential than the public believed. The differences indicate that the perceived influence of government, industry, and political groups was viewed as stronger by the public than by producers. These differences of opinion might also reflect that dairy farmers do not wish to be told which production practices are acceptable, whereas many members of the public, being disconnected from production agriculture, were counting on related groups to influence policy and practices. Note also that the relative oversampling of women in the public sample likely helps to explain at least partly the differences in perceptions between the public and producer views, as sex of respondent is an important explanatory below in voting and premium preferences.

\section{Potential Votes and Premiums Related to Production Practices}

Respondents to the public surveys were asked about potential votes to limit or ban 3 production practices as well as paying a premium for milk produced without recombinant bovine somatotropin (rbST), also called recombinant bovine growth hormone (rbGH). Specifically, the questions asked were

- Would you vote to limit antibiotic use for cattle to only disease treatment?

- Would you vote to ban castration without the use of pain control?

- Would you vote to ban the use of $\mathrm{rbST} / \mathrm{rbGH}$ in the dairy industry?

- Would you pay a premium for milk produced without $\mathrm{rbST} / \mathrm{rbGH}$ ?

Potential answers to each question were "yes," "no," or "don't know."
This research does not propose or assert that any of these restrictions are likely, but it has often been the case in US animal welfare and production practice legislation for multiple species to be affected by practice restrictions. The restrictions on practices chosen were those that have received some attention from certain groups or organizations. Antibiotic use on US dairy operations includes medicated milk replacer $(57.5 \%$ of operations), dry-cow treatments (90\% of operations), and mastitis (16\% of cows; USDA-APHIS, 2008). However, there is a great deal of concern and misunderstanding in the public about antibiotic use on dairy operations (Barlow, 2011). Pain control in castration has been an issue most related to the pork industry but any potential restriction might apply to multiple species. We also recognize that all milk contains bST. In this case, we used "rbST-free" in the lay parlance to indicate milk produced without rbST supplementation.

To examine the socio-economic factors related to the stated voting and premium preferences of these production practices, we used a multinomial logit regression. The multinomial logit estimates the probability of the answers with one category omitted. In this case, we omitted the "yes" category, meaning that the coefficients should be interpreted as relative to that answer. We focus on the marginal effects, which are probability changes either per unit (for continuous variables) or for that characteristic occurring (for discrete changes), in Tables 7 and 8, whereas the coefficients are available in Table A1 in the Appendix. Thus, one should interpret a positive effect as meaning an increase in the probability of voting that way for the variable in question. For example, the positive marginal probability of sex for the "no" vote indicates that men were more likely to vote "no" than were women. Further, the marginal effects indicate the percentage change in probability either at the mean for continuous variables or for the "1" value for discrete explanatory variables. Thus, the marginal effect of 0.0841 for sex on the "no" vote for restricting antibiotics indicates that men were about $8 \%$ more likely to vote "no" than were women.

Although the marginal effects varied, several patterns emerged across these voting or premium preferences. As age increased, respondents were less likely to vote "no" on all 3 production bans. Men were more likely to vote against these proposals or decline to pay a premium compared with women. Higher household income was associated with increased likelihood of a "yes" vote on hypothetical antibiotic and castration restrictions as well as paying a premium for milk produced without rbST. Weekly household food expenditure was positively related to the production practice bans but negatively related to paying a premium for milk produced without rbST. Research has demonstrated that voters 


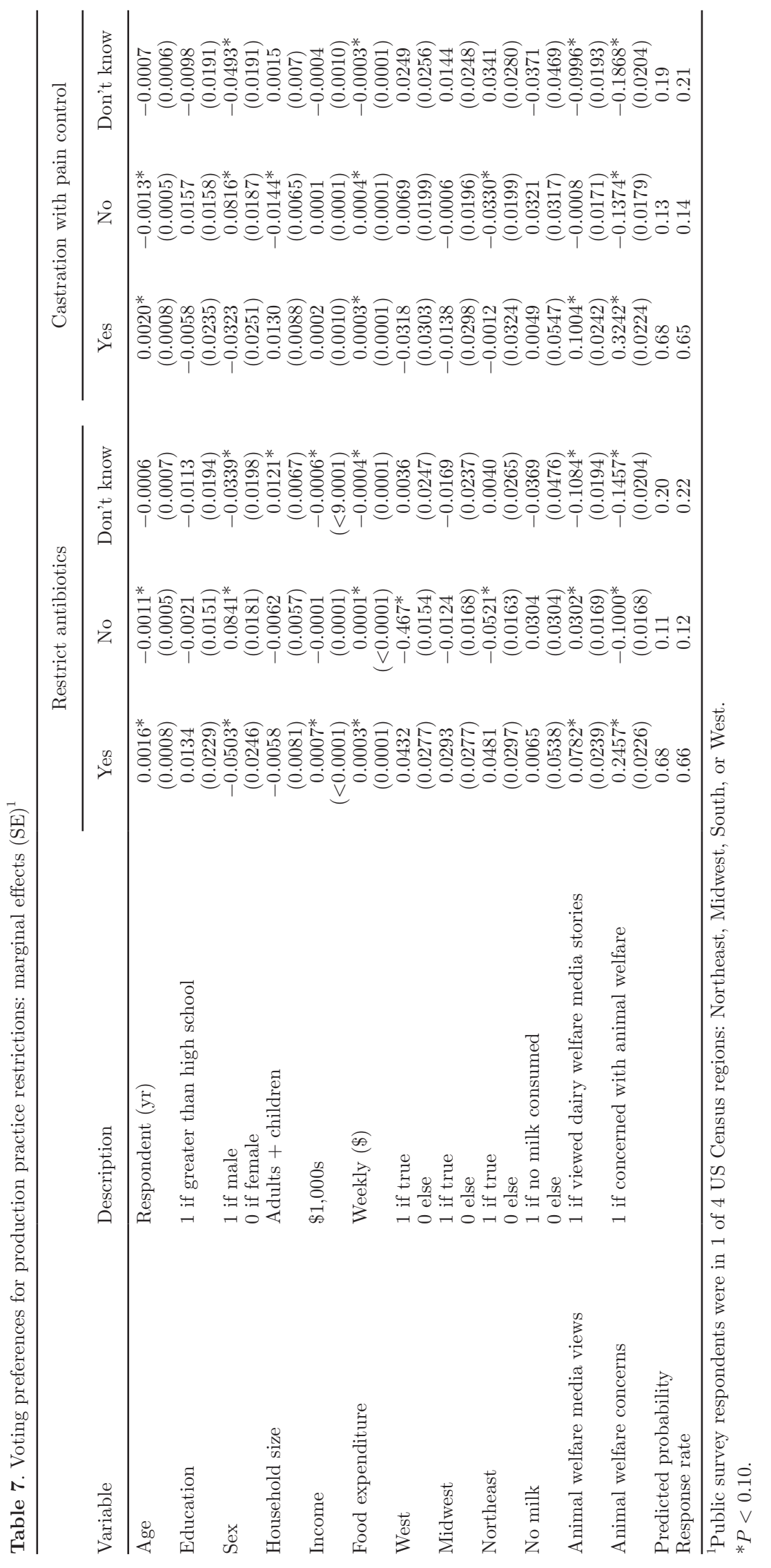


WOLF ET AL.

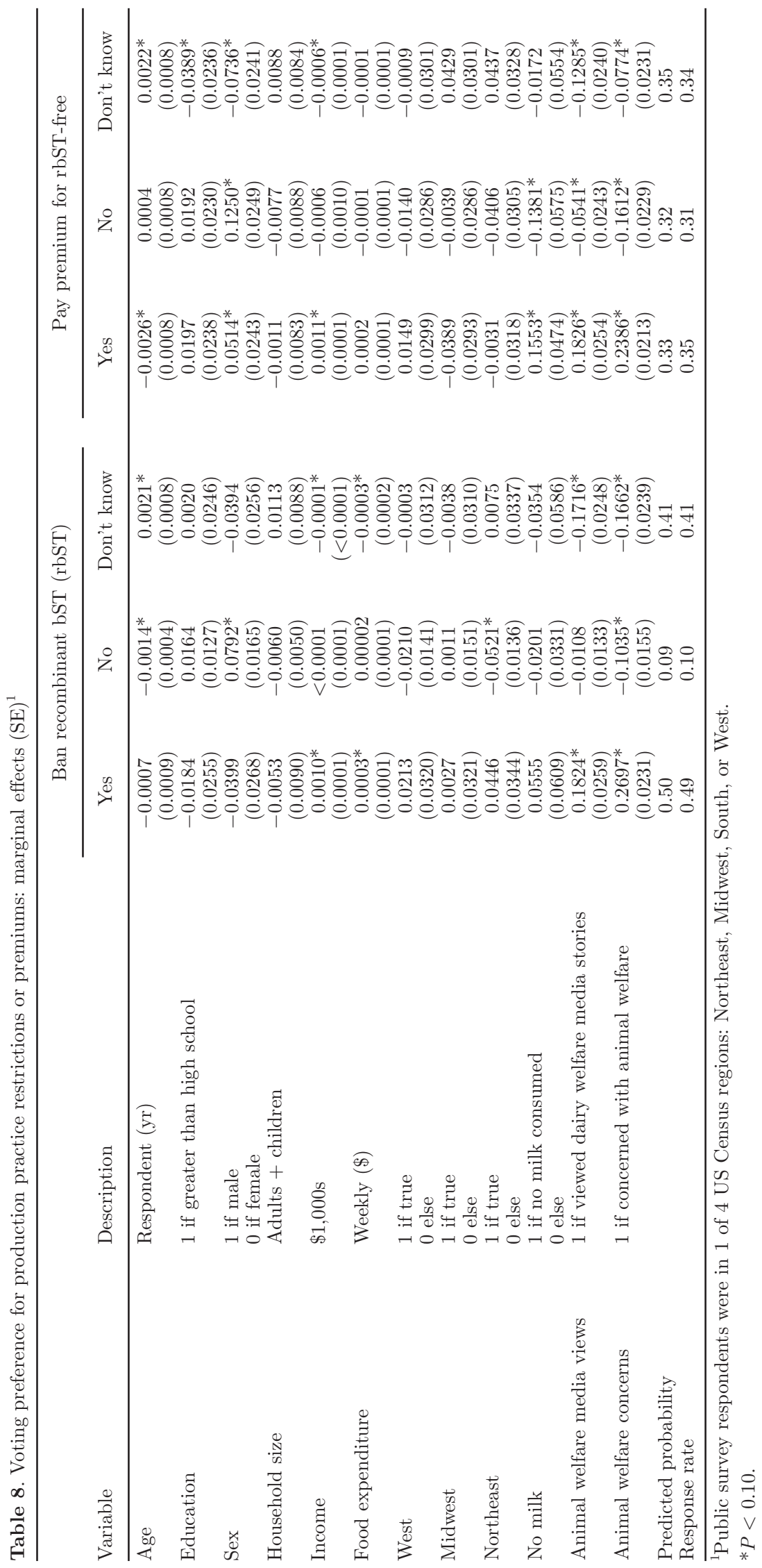


often do not consider the potential for higher food costs that would result from bans on agricultural production practices (Tonsor and Wolf, 2010). Regional variables, which represent differences from the south region, were generally not significant. In every case, respondents who indicated they had viewed media related to dairy cattle welfare were more likely to vote "yes" on the production restrictions or paying a premium. These effects were relatively large, ranging from an increase in probability of 7.8 to $18.3 \%$. Similarly, those respondents who indicated they were concerned with dairy cattle welfare in the United States were much more likely to vote "yes" or were willing to pay a premium with those values being a marginal probability increase of about $24 \%$ to more than $32 \%$.

The relative ability of this estimation to predict voting outcome can be assessed using the last 2 rows of Tables 7 and 8. The "predicted probability" is the multinomial model prediction that a respondent would indicate that response, whereas the "response rate" is the actual percentage of each response category. As the results demonstrate, the model accurately predicted the response rate. About two-thirds of respondents indicated they would vote to limit antibiotic use and ban castration without pain control. A minority, 49\%, indicated they would vote to ban rbST and about onethird, 35\%, indicated they would pay a premium for milk produced without rbST. In every case, a large portion of respondents answered "don't know." Presumably, the public respondents who answered "don't know" might be convinced either way, depending on information gathered before any actual vote.

\section{CONCLUSIONS}

Utilizing the results of a 2014 survey of US public and dairy farmer opinions and attitudes, this study supplies a comprehensive look at how the public perceived dairy cattle welfare and how those related to farmer perceptions. These results can be used to guide educational programs - for both producers and the public - as they indicate many gaps in knowledge that may be fertile avenues to improve societal views of dairy cattle welfare in the United States. Public respondents indicated they believed dairy cattle welfare was a concern. Respondents generally disagreed that low milk prices were more important than dairy cattle welfare. Many public respondents agreed that dairy farmers faced trade-offs between profitability and dairy cattle welfare. The majority of public respondents did not recall seeing a media story on dairy cattle welfare. Of those that had seen a media story on dairy cattle welfare, most had seen it on television or the Internet. The most reliable source of animal welfare information was thought to be the USDA, followed by the HSUS. The USDA and farmers were viewed as the most influential parties affecting dairy cattle welfare. With respect to who has the most influence on the welfare of dairy cattle in the United States, both the public and farmers viewed dairy producers as very influential. Comparing the relative level of influence revealed that the public respondents generally felt that groups (e.g., USDA, HSUS, NMPF) had more influence, whereas farmers felt that individuals (i.e., farmers, veterinarians, consumers) had more influence. Examining voting preferences for hypothetical restrictions on production practices revealed that older respondents, women, those in households with higher income and more food expenditures, as well as respondents who had viewed animal welfare stories in the media were more likely to vote for the hypothetical restrictions and indicated that dairy cattle welfare in the United States was a concern. Limitations of this research include that the public sample, being targeted to primary shoppers, was older, more educated, and more female than the general US population. Additionally, these surveys are subject to hypothetical bias. Finally, with limited space and in keeping the survey manageable, we did not examine the level of understanding that the US public has with dairy production practices and technologies other than to allow them to indicate "don't know." The level of public understanding, where and how they acquire information about milk production, and how the engagement of citizens and dairy producers could affect policy and production would be areas for future research.

\section{ACKNOWLEDGMENTS}

This research was funded by US Department of Agriculture National Institute of Food and Agriculture (Washington, DC; grant no. 2012-68006-30178). All views expressed here are those of the authors and should not be attributed to the US Department of Agriculture.

\section{REFERENCES}

Asplund, N. M., D. L. Forster, and T. T. Stout. 1989. Farmers use of forward contracting and hedging. Review of Futures Markets $8: 24-37$.

Barlow, J. 2011. Antimicrobial Resistance and the Use of Antibiotics in the Dairy Industry: Facing Consumer Perceptions and Producer Realities. Western Canadian Dairy Seminar Proceedings. Accessed Mar. 2, 2016. http://www.wcds.ca/proc/2011/Manuscripts/ Barlow.pdf.

Barrett, R., and L. Bergquist. 2013. Dairy industry leaders decry video showing abuse of cows. Milwaukee Journal Sentinel. Accessed Dec. 18, 2015. http://www.jsonline.com/business/undercovervideo-prompts-nestle-to-drop-milk-supplied-by-greenleaf-dairyb99160610z1-235244161.html.

Boogaard, B. K., B. B. Bock, S. J. Oosting, J. S. C. Wiskerke, and A. J. van der Zijpp. 2011. Social acceptance of dairy farming: The 
ambivalence between the two faces of modernity. J. Agric. Environ. Ethics 24:259-282.

Cardoso, C. S., M. J. Hotzel, D. M. Weary, J. A. Robbins, and M. A. G. von Keyserlingk. 2016. Imagining the ideal dairy farm. J. Dairy Sci. 99:1663-1671.

Curtis, S. E. 1987. Public mood and how we respond. J. Dairy Sci. 70:2708-2710.

Dillman, D. A., J. D. Smyth, and L. M. Christian. 2009. Internet, Mail and Mixed-Mode Surveys: The Tailored Design Method. John Wiley \& Sons, Hoboken, NJ.

Ellis, K. A., K. Billington, B. McNeil, and D. E. F. McKeegan. 2009 Public opinion on UK milk marketing and dairy cow welfare. Anim. Welf. 18:267-282.

Fisher, R. J. 1993. Social desirability bias and the validity of indirect questioning. J. Consum. Res. 20:303-315.

Fraser, D., D. M. Weary, E. A. Pajor, and B. N. Milligan. 1997. A scientific conception of animal welfare that reflects ethical concerns. Anim. Welf. 6:187-205.

Humane Farm Animal Care. 2014. Animal Welfare Standards. Accessed January 2014. http://certifiedhumane.org/wpcontent/ uploads /2014/01/Comp.Standards. Comparison.Chart_. wappendix.11.26.13.pdf.

Louviere, J. J., T. Islam, N. Wasi, D. Street, and L. Burgess. 2008. Designing discrete choice experiments: Do optimal designs come at a price? J. Consum. Res. 35:360-375.

Lusk, J., and F. B. Norwood. 2009. Bridging the gap between laboratory experiments and naturally occurring markets: An inferred valuation method. J. Environ. Econ. Manage. 58:236-250.

Maddala, G. S. 1983. Limited-Dependent and Qualitative Variables in Econometrics. Cambridge University Press, Cambridge, UK.

Mench, J. 2003. Assessing animal welfare at the farm and group level: A United States perspective. Anim. Welf. 12:493-503.

Miele, M., I. Veissier, A. Evans, and R. Botreau. 2011. Animal welfare: A dialogue between science and society. Anim. Welf. 20:103-117.

Miller, D. J. 2014. Great Lakes Cheese is 'outraged' over mistreatment of cows. Cleveland Plain Dealer. November 11, 2014. Accessed Oct. 28, 2015. http://www.cleveland.com/metro/index. ssf/2014/11/great_lakes_cheese_is_outraged.html.

NMPF (National Milk Producers Federation). 2014. National Dairy FARM Program: 2014 Year in Review. Accessed Nov. 13, 2014. http://www.nmpf.org/publications/national-dairy-farm-program.

Olynk, N. J., G. T. Tonsor, and C. A. Wolf. 2010. Consumer willingness to pay for livestock credence attribute claim verification. J. Agric. Resour. Econ. 35:261-280.

Paul, J. 2015. Colorado authorities investigating dairy cow abuse video: Workers fired. The Denver Post. June 11, 2015. Accessed Oct. 28, 2015. http://www.denverpost.com/news/ci_28295679/ colorado-authorities-investigating-dairy-plant-abuse-videoworkers? source=infinite-up.

Sjostrom, L. 2015. Tail docking ends for NMPF Members, FARM participants in 2016. Bovine Vet Online. Accessed Nov. 9, 2015. http://www.bovinevetonline.com/news/tail-docking-ends-nmpfmembers-farm-participants-2016.

Te Velde, H., N. Aarts, and C. Van Woerkum. 2002. Dealing with ambivalence: Farmers' and consumers' perceptions of animal welfare in livestock breeding. J. Agric. Environ. Ethics 15:203-219.

Tonsor, G. T. 2011. Consumer inferences of food safety and quality. Eur. Rev. Agric. Econ. 38:213-235.

Tonsor, G. T., and C. A. Wolf. 2010. Drivers of resident support for animal care oriented ballot initiatives. J. Agric. Appl. Econ. 42:419-428.

US Census Bureau. 2015. Topics. Accessed Jun. 19, 2015. http://www. census.gov/topics/population.html.

USDA-APHIS (USDA Animal and Plant Health Inspection Service) 2008. Antibiotic Use on U.S. Dairy Operations, 2002 and 2007. APHIS Info Sheet. Accessed March 2, 2016. https://www.aphis. usda.gov/animal_health/nahms/dairy/downloads/dairy07/ Dairy07_is_AntibioticUse.pdf.

USDA-NASS (USDA National Agricultural Statistics Service). 2012 Agricultural Census Dairy Cattle and Milk Production Highlights. Accessed Aug. 30, 2015. http://www.agcensus.usda.gov/ Publications/2012/Online_Resources/Highlights/Dairy_Cattle_ Milk_Prod/Dairy_Cattle_and_Milk_Production_Highlights.pdf.

USDA-NASS (USDA National Agricultural Statistics Service). 2015 Milk Production, February 2015. Accessed Jun. 19, 2015. http:// usda.mannlib.cornell.edu/usda/nass/MilkProd//2010s/2015/ MilkProd-02-20-2015.pdf.

Vanhonacker, F., W. Verbeke, E. Van Poucke, and F. A. M. Tuyttens. 2008. Do citizens and farmers interpret the concept of farm animal welfare differently? Livest. Sci. 116:126-136.

von Keyserlingk, M. A. G., J. Rushen, A. M. de Passillé, and D. M. Weary. 2009. Invited review: The welfare of dairy cattle-Key concepts and the role of science. J. Dairy Sci. 92:4101-4111.

Webb, T. 2010. Land O'Lakes supplier's animal cruelty case dropped. Pioneer Press. Accessed Dec. 18, 2015. http://www.twincities. com/business/ci_14712665.

Wolf, C., G. Tonsor, M. McKendree, D. Thomson, and J. Swanson. 2015a. U.S. Dairy Farmer Welfare Perceptions and Attitudes: Survey Summary. MSU AFRE Staff Paper 2015-04. Michigan State University, East Lansing.

Wolf, C., G. Tonsor, L. Polzin, M. McKendree, D. Thomson, and J Swanson. 2015b. U.S. Public Dairy Cattle Welfare Perceptions and Attitudes: Survey Summary. MSU AFRE Staff Paper 2015-03. Michigan State University, East Lansing. 


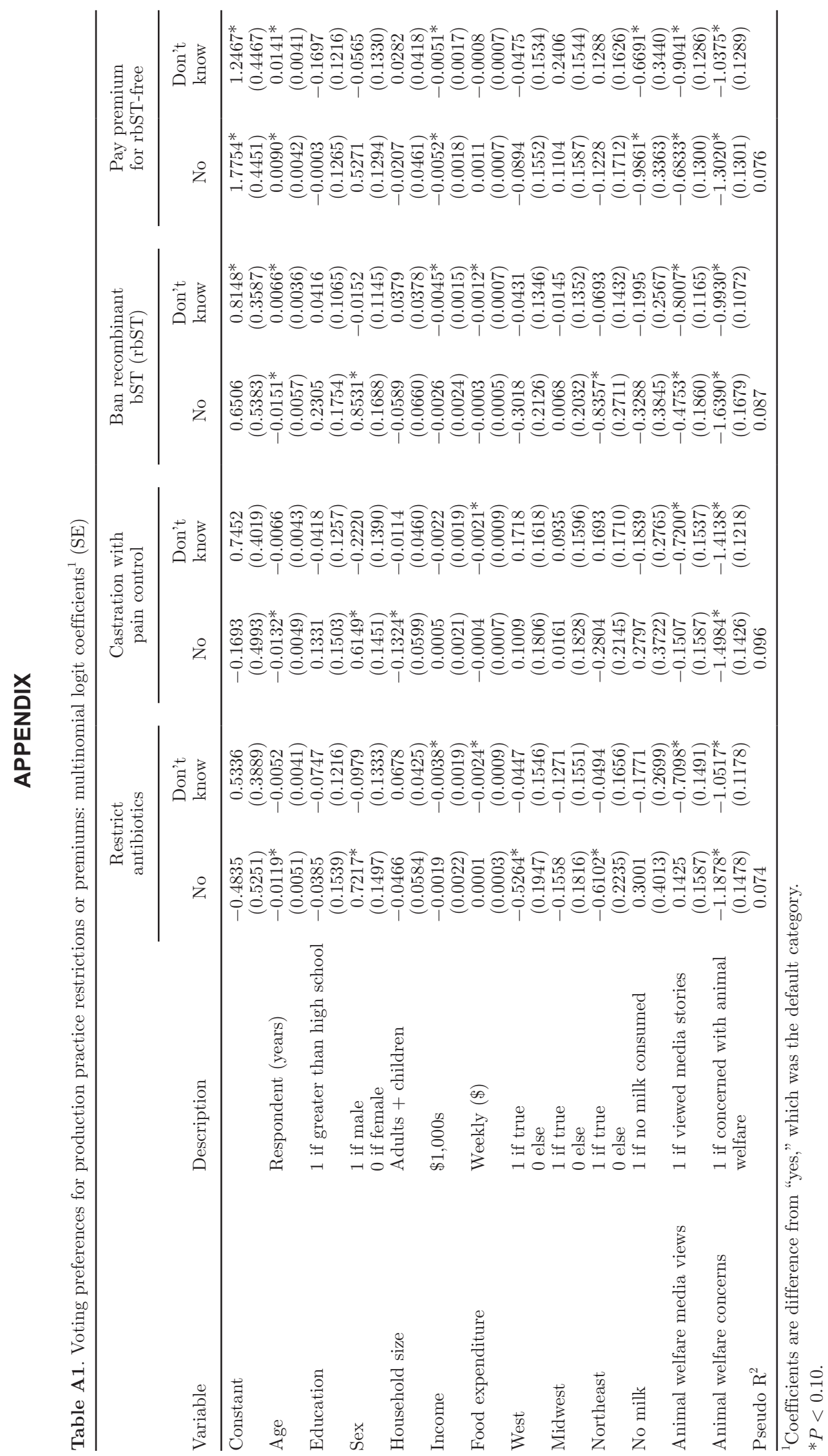

